\title{
Produtividade biológica de genótipos de tomateiro em sistema hidropônico no outono/inverno
}

\author{
Antonio AR de Albuquerque Neto; Roberta MN Peil \\ UFPel, Depto. Fitotecnia, C. Postal 354, 96010-900 Pelotas-RS; agroquerque@gmail.com; rmpeil@ufpel.tche.br
}

\section{RESUMO}

O crescimento da planta de tomateiro depende de numerosos fatores, entre os quais se podem mencionar o genótipo, a radiação solar global incidente, a temperatura, a nutrição, o suprimento de água e a concentração de $\mathrm{CO}_{2}$, que atuam conjuntamente em complexa interação. Este trabalho teve o objetivo de avaliar a produtividade biológica de sete genótipos de tomateiro em cultivo hidropônico, no ciclo de outono/inverno caracterizado por baixa disponibilidade de radiação solar global, enfocando aspectos vegetativos e produtivos, a partição dos fotoassimilados e a eficiência no uso da radiação fotossinteticamente ativa (PAR), a fim de definir o(s) mais promissor(es) para o cultivo em casa de vegetação no sul do Rio Grande do Sul. O delineamento experimental utilizado foi em blocos casualizados com 7 tratamentos (genótipos) e 3 repetições, com 6 plantas por parcela. Dos genótipos utilizados, cinco pertencem ao grupo dos minitomates: Tomate Cereja Pendente Yubi Feltrin ${ }^{\circledR}$ (hábito determinado), Cereja Vermelho ISLA ${ }^{\circledR}$, Minitomate Pêra Amarelo TOP SEED ${ }^{\circledR}$, Grape (não comercial), Flavor Top (não comercial). Além desses, estudaram-se os genótipos Tomate Santa Cruz Kada Gigante TOP SEED ${ }^{\circledR}$ e Tomate Gaúcho TOP SEED ${ }^{\circledR}$. As avaliações foram produtividade $\left(\mathrm{g} \mathrm{m}^{-2}\right)$ de matéria fresca e seca de hastes, folhas e frutos; área foliar; altura e compacidade de planta; radiação solar global e PAR incidentes. Os genótipos mais promissores para o cultivo em épocas de baixa disponibilidade de radiação solar são Kada Gigante, do tipo Santa Cruz, e Cereja Yubi de crescimento determinado, do grupo dos minitomates, por apresentarem produtividade de frutos superiores e uma alta eficiência no uso da PAR.

Palavras-chave: Solanum lycopersicon, cultivo protegido, cultivo sem solo, radiação solar, crescimento.

\section{ABSTRACT \\ Performance of tomato genotypes in hydroponic system and fall/winter crop-season}

Genotype, incident global solar radiation, temperature, nutrient, water and $\mathrm{CO}_{2}$ availability are some of the factors that in interaction can influence the growth of tomato plants. This study aimed to evaluate seven genotypes of tomato in relation to their biological productivity in hydroponics and fall/winter crop-season, characterized by low solar radiation availability, focusing vegetative and productive aspects, fotoassimilates partitioning and photosynthetic active radiation (PAR) use efficiency in order to determine the most promising for greenhouse cultivation in southern Rio Grande do Sul. The experimental design was randomized blocks with 7 treatments (genotypes) and 3 replications with 6 plants per plot. Among the evaluated genotypes, five are minitomatoes: Cereja Pendente Yubi Feltrin $^{\circledR}$ (determinated growth habit), Cereja Vermelho ISLA ${ }^{\circledR}$, Minitomate Pêra Amarelo TOP SEED ${ }^{\circledR}$, Grape (no commercial), Flavor Top (no commercial). Also, Santa Cruz Kada Gigante TOP $S E E D^{\circledR}$ and Gaúcho TOP SEED ${ }^{\circledR}$ tomato varieties were evaluated. Fresh and dry matter productivity $\left(\mathrm{g} \mathrm{m}^{-2}\right)$ of leaves, stems and fruits; leaf area; plant height and compactness; incident global and PAR solar radiations were evaluated. The genotypes Kada Gigante, of Santa Cruz group, and Cereja Pendente Yubi Feltrin ${ }^{\circledR}$, of determinated growth habit and minitomato group, presented higher fruit yield and PAR use efficiency. So, these genotypes can be considered the most promising for growing in low solar radiation availability crop-season.

Keywords: Solanum lycopersicon, protected cultivation, soilless cultivation, solar radiation, growth.

(Recebido para publicação em 22 de novembro de 2011; aceito em 18 de setembro de 2012) (Received on November 22, 2011; accepted on September 18, 2012)

\begin{abstract}
A olericultura brasileira está dando um salto qualitativo com a produção de diversas hortaliças em cultivo hidropônico em ambientes protegidos. A aplicação desta técnica esta sendo expandida para a produção de oleráceas de fruto, com grande enfoque para o tomateiro. Desta forma, a plasticultura vem alargando seu campo de atuação em relação à sazonalidade e regionalidade. Épocas e regiões que anteriormente não se mostravam propícias à produção, caracterizando-se por baixas temperaturas, excesso de chuva ou, por outro lado, forte radiação, altas temperaturas e chuvas escassas, hoje em dia, podem ser
\end{abstract}

pólos de produção de hortaliças, como é o caso da serra gaúcha e de regiões semiáridas e áridas (nordeste brasileiro, Israel, norte da África e sul da Espanha).

No entanto, mesmo que se tenham informações gerais acerca dos diversos aspectos técnicos do cultivo em ambiente protegido, há ainda a carência de informações específicas relativas ao comportamento de genótipos em determinadas regiões, visto que existem efeitos regionais, oriundos da latitude e da altitude, definindo as condições climáticas, que em consequência, determinam as técnicas de manejo.

Quanto aos estudos praticados para o aprimoramento da produção neste ambiente artificial de cultivo, pode-se, salvando alguns outros componentes, simplificar em três áreas de abrangência: condições ambientais internas, em decorrência do tipo de estrutura e do material usado na confecção da estufa agrícola (Duarte et al., 2011); manejo fitotécnico do material genético cultivado (Andriolo et al., 2004a) e o manejo do ambiente radicular (solo ou cultivo sem solo) (Andriolo et al.; 2004b; Valandro et al., 2007).

O tomateiro é uma das mais importantes hortaliças cultivadas no Brasil, sendo sua utilização muito variada e 
com grande número de tipos de frutos existentes (Gusmão et al., 2000). Dentre estes, encontram-se os tomates do tipo cereja, que vêm sendo comumente encontrados nos mercados, principalmente nos grandes centros, onde alcançam preços bastante atrativos aos produtores que se localizam próximo aos locais de comercialização.

De acordo com informações da Seção de Economia e Desenvolvimento da CEASA do Rio Grande do Sul, o volume de tomate cereja comercializado cresceu de 129,33 toneladas em 1998 para 216,86 toneladas em 2010 (CEASA-RS, 2011). Entretanto, o tomate do tipo salada tem um volume comercializado bem maior. Na CEAGESP foram comercializados nos últimos cinco anos, em média 23.024 t por mês de tomate salada, sendo o volume comercializado maior no mês de janeiro (24.071 t) e menor no mês de julho (21.563 t) (AGRIANUAL, 2010).

Segundo Nuez (2001), o desenvolvimento da planta de tomateiro depende de numerosos fatores, entre os quais se podem mencionar o material genético, a iluminação, a temperatura, a nutrição, o abastecimento de água e a concentração de $\mathrm{CO} 2$, que atuam conjuntamente em complexa interação.

O Rio Grande do Sul é o estado mais austral do território brasileiro, e, em virtude disso, ocorre no inverno a diminuição do número de horas de luz e da intensidade de incidência da radiação solar, o que afeta o balanço de energia na superfície refletindo-se na redução da temperatura do ar (Pereira et al., 2002). Intensificando a redução da radiação solar, tem-se alta nebulosidade, que em condições de clima temperado com inverno úmido, característico dos meses de inverno para a região de Pelotas, é bastante comum ocorrer. Essas características climáticas são desfavoráveis ao cultivo do tomateiro, visto que o desenvolvimento normal da cultura só ocorre quando a quantidade de radiação recebida for superior ao nível trófico ou ponto de compensação lumínico. Este é o ponto em que se tem o equilíbrio entre a absorção fotossintética e a liberação oxidativa de $\mathrm{CO}_{2}$ (Taiz \& Zeiger, 2009), que no caso do tomateiro é de $8,4 \mathrm{MJ} \mathrm{m}^{-2}$ dia $^{-1}$ (FAO, 1990; Andriolo, 1999). Esta condição de inverno gera uma janela de entressafra na tomaticultura nos meses de maio até agosto no Rio Grande do Sul, período este em que os frutos de tomate alcançam o mais alto valor no mercado .

Dentre os fatores que podem influenciar na acumulação e repartição da massa seca entre os órgãos da parte aérea, podem ser citados: radiação solar interceptada pela cultura, temperatura, densidade de cultivo, que está relacionada à competição entre plantas, poda de folhas, carga de frutos, disponibilidade de nutrientes e genótipo (Andriolo et al., 1997; Papadopoulos et al., 1997; Rattin et al., 2003; Andriolo et al., 2004a).

A variabilidade genética pode ser uma grande ferramenta da agricultura. $\mathrm{Na}$ tomaticultura ela está explicita nas múltiplas formas e cores que os frutos do tomateiro podem apresentar; assim como no hábito de crescimento do caule, que é determinado quando as plantas são rasteiras e o desenvolvimento da parte vegetativa acontece separado temporalmente da parte generativa (vegeta, floresce e frutifica em períodos seqüenciados) e indeterminado, quando as plantas crescem e florescem concomitantemente, sendo que a partir da emissão do primeiro cacho floral, ocorre a emissão continua de três folhas seguidas por um cacho (Tanaka et al., 1974). Mais sutilmente, esta variabilidade pode ser constatada na adaptabilidade a condições climáticas extremas e na produção e distribuição de fotoassimilados entre seus órgãos, entre outras características.

Este trabalho objetiva estudar a produtividade biológica (produção e distribuição de biomassa e eficiência no uso da radiação solar) de sete genótipos de tomateiro em sistema hidropônico, a fim de definir o(s) mais promissor(es) para o cultivo em estufa plástica no outono-inverno do sul do Rio Grande do Sul.

\section{MATERIAL E MÉTODOS}

O experimento foi conduzido entre 01 de abril e 31 de julho de 2010, na Faculdade de Agronomia Eliseu Maciel (FAEM), da UFPel, situado no município de Capão do Leão-RS (31 ${ }^{\circ} 52$ 'S, $52^{\circ} 21^{\prime} \mathrm{O}$, altitude $\left.13 \mathrm{~m}\right)$. O clima da região, conforme classificação de Köppen-
-Geiger ${ }^{1}$ é Cfa, temperado úmido com verão quente.

O cultivo foi realizado em casa de vegetação modelo teto em arco, com estrutura metálica, compreendendo uma área de $210 \mathrm{~m}^{2}(10 \times 21 \mathrm{~m})$ com 4,5 m de altura máxima e $3,5 \mathrm{~m}$ de pé direito, disposta no sentido Norte-Sul, coberta com filme de polietileno de baixa densidade (150 $\mu \mathrm{m}$ de espessura). O solo apresentava-se nivelado e coberto com filme de polietileno dupla face (branco-preto) de $150 \mu \mathrm{m}$ de espessura, com a face branca exposta. Durante o período de execução do experimento, o manejo da temperatura e das trocas gasosas foi realizado através da ventilação natural, mediante abertura e fechamento das janelas laterais e portas da estrutura, sendo que em dias e horários que ocorreram baixas temperaturas, fortes ventos, alta umidade relativa do ar e chuvas, a casa de vegetação foi mantida parcial ou totalmente fechada.

A semeadura de sete genótipos foi efetuada em vermiculita acondicionada em bandejas plástica, no dia 12 de março de 2010. A repicagem foi realizada no dia 26 de março de 2010, quando as plântulas, apresentando a primeira folha definitiva, foram transferidas para espuma fenólica de 2,5 × 2,5 x $3 \mathrm{~cm}$, sendo então dispostas em 'berçário' constituído por um canal de cultivo NFT (técnica da lâmina de nutrientes). $\mathrm{O}$ dia $1^{\circ}$ de abril foi considerado como a data de inicio do experimento, quando as plantas ainda no berçário foram dispostas em 3 blocos.

No dia 20 de abril, as plantas de cada genótipo, respeitando os blocos já definidos, foram estabelecidas na totalidade da área do sistema hidropônico, utilizando espaçamento linear de 0,30 m entre plantas, perfazendo a densidade de 3,9 plantas $\mathrm{m}^{-2}$. O sistema foi constituído por 12 canais de madeira ( $7,5 \mathrm{~m}$ de comprimento e $0,35 \mathrm{~m}$ de largura), dispostos em 6 linhas duplas, com distância entre linhas duplas de $1,2 \mathrm{~m}$ e distância entre linhas simples de $0,5 \mathrm{~m}$.

Os canais foram apoiados sobre cavaletes galvanizados de $0,5 \mathrm{~m}$ de altura máxima, instalados de forma a proporcionar uma declividade de $2 \%$

${ }^{1} \mathrm{http}: / /$ meteo12.nforum.biz/t17-classificacaoclimatica-de-koppen 
para o escoamento da solução nutritiva. Internamente, os canais de madeira foram revestidos com filme de polietileno dupla face branco-preto, de maneira a formar canais de plástico, com exposição externa da face branca, o que minimiza o aquecimento da solução nutritiva e evita a proliferação de algas. Na cota mais baixa destes canais, encontrava-se um canal coletor, que também era de madeira e revestido por filme de polietileno dupla face branco-preto, com a função de conectar a porção final dos canais de cultivo, coletar e conduzir o drenado da solução nutritiva até o reservatório. Utilizou-se um reservatório de solução nutritiva de polietileno com capacidade de 1000 L enterrado na extremidade de cota mais baixa do sistema de cultivo hidropônico.

Um conjunto moto-bomba de $1 / 4 \mathrm{HP}$, fixado no reservatório, impulsionava a solução para as extremidades de maiores cotas dos canais através de um cano de PVC de $25 \mathrm{~mm}$, na vazão de $4 \mathrm{~L} \mathrm{~min}^{-1}$. A partir desse ponto, devido à declividade, a solução nutritiva percorria a base dos canais de cultivo, formando uma lâmina fina e, após passar pelas raízes nos canais de cultivo, a solução nutritiva chegava ao canal coletor fechando o sistema. O fornecimento da solução foi programado por um temporizador, realizando-se fluxos de irrigação das $8: 00 \mathrm{~h}$ às $18: 00 \mathrm{~h}$ durante 15 minutos, com intervalos de 45 minutos.

A solução nutritiva utilizada foi a recomendada por Rocha (2009) para a cultura do tomateiro. Diariamente, a solução nutritiva foi monitorada através das medidas de condutividade elétrica (empregando-se condutivímetro manual digital) e pH (empregando-se pHmetro manual digital). A condutividade elétrica foi mantida em $1,8 \mathrm{dS} \mathrm{m}^{-1}$ e, quando este valor sofria uma diminuição ou um aumento da ordem de $15 \%$, foi feita a sua correção, através de soluções estoques concentradas, ou de água, respectivamente. $\mathrm{O}$ pH foi mantido entre 5,5 e 6,5, através da adição de solução de correção à base de hidróxido de potássio $(\mathrm{KOH}$ $1 \mathrm{~N})$ ou ácido sulfúrico $\left(\mathrm{H}_{2} \mathrm{SO}_{4} 1 \mathrm{~N}\right)$.

$\mathrm{O}$ delineamento experimental utilizado foi em blocos casualizados com 7 tratamentos (genótipos) e 3 repetições. Cada parcela foi constituída por 6 plantas, selecionando-se as duas plantas centrais para a coleta de dados. Dos genótipos utilizados, cinco pertencem ao grupo dos minitomates: Tomate Cereja Pendente Yubi Feltrin ${ }^{\circledR}$ (hábito determinado), Cereja Vermelho ISLA ${ }^{\circledR}$, Minitomate Pêra Amarelo TOP SEED ${ }^{\circledR}$, Grape (não comercial), Flavor Top (não comercial); e dois do tipo mesa: Tomate Santa Cruz Kada Gigante TOP SEED ${ }^{\circledR}$ e Tomate Gaúcho TOP SEED ${ }^{\circledR}$, do grupo salada. Excetuando-se o genótipo Tomate Cereja Pendente Yubi Feltrin ${ }^{\circledR}$ (hábito determinado), todos os demais apresentam hábito de crescimento indetermindo.

Os genótipos de crescimento indeterminado foram conduzidos com haste única, fazendo-se a desbrota das hastes laterais periodicamente, enquanto o genótipo de hábito determinado foi mantido sem podas, sendo apenas tutorado. O tutoramento foi através de uma fita de ráfia presa na linha de arame disposta 3,0 $\mathrm{m}$ acima da linha de cultivo e sustentada pela estrutura da estufa. $\mathrm{O}$ monitoramento e o controle de doenças e pragas foram realizados de acordo com práticas alternativas e convencionais.

As avaliações realizadas foram em relação à produtividade $\left(\mathrm{g} \mathrm{m}^{-2}\right)$ da biomassa (matéria fresca e seca) vegetativa (folhas e hastes) e reprodutiva (frutos), à área foliar e à altura das plantas, estabelecendo-se a eficiência no uso da PAR ou radiação fotossinteticamente ativa (relação de gramas de matéria seca total produzida por MJ de radiação PAR incidente por unidade de área no interior da casa de vegetação).

A matéria aérea fresca e seca acumulada pela parte aérea das plantas ao final do experimento (121 dias após o inicio do experimento ou 140 dias após a semeadura) foi avaliada. Foram utilizadas duas plantas por repetição (no total, 6 plantas por genótipo), as quais foram separadas em três frações: folhas, hastes e frutos (considerando-se a totalidade dos frutos colhidos). As frações foram pesadas, obtendo-se a matéria fresca, sendo então secas separadamente em estufa de ventilação forçada a $65^{\circ} \mathrm{C}$, até peso constante. Após a secagem, as diferentes frações foram novamente pesadas em balança de precisão, obtendo-se as suas respectivas matérias secas. O material de desbrotas, desfolhas antecipadas e todos os frutos colhidos durante o processo produtivo foram acrescentados às frações correspondentes. A matéria fresca e seca total da parte aérea da planta correspondeu à soma das matérias de folhas, caules e frutos. A partir dessas análises, determinou-se a distribuição de biomassa entre os órgãos aéreos das plantas. Também foi avaliada a área foliar acumulada ao final do experimento, através de um equipamento medidor de imagens (LI-COR, modelo 3100) e determinada a compacidade da planta a partir da relação área foliar/altura.

A radiação solar global no exterior $\left(\operatorname{Rg}_{\text {ext }}\right)$ da casa de vegetação foi obtida a partir dos dados registrados pela Estação Agroclimatológica da UFPel, localizada a aproximadamente $500 \mathrm{~m}$ do local do experimento e a radiação global interna $\left(\mathrm{Rg}_{\text {int }}\right)$ foi estimada em $76 \%$ da Rgext, e a PAR em $40 \%$ da $\mathrm{Rg}_{\text {int }}$, segundo índices obtidos por Beckmann et al. (2006) em trabalho realizado na mesma casa de vegetação.

Os dados obtidos foram submetidos à análise da variância (teste F) e quando houve significância estatística $(\mathrm{p}<0,05)$, as médias das cultivares foram comparadas pelo teste de Tukey.

\section{RESULTADOS E DISCUSSÃO}

\section{Produtividade de matéria fresca e} seca - A análise de variância dos dados de produção de matéria fresca (MF) e seca (MS) demonstrou que houve diferenças significativas pelo teste $\mathrm{F}$ $(<0,05)$ para o total da parte aérea das plantas, hastes, folhas e frutos, entre os genótipos de tomateiros estudados. As médias apresentadas na Tabela $1 \mathrm{de}$ monstram que a produtividade de $\mathrm{MF}$ e MS da parte aérea foi maior no genótipo Kada Gigante. Apesar do seu hábito de crescimento e do menor tamanho dos frutos, o genótipo Cereja Yubi determinado apresentou produtividade de MF e MS da parte aérea semelhante ao Kada Gigante. O desenvolvimento da parte vegetativa do tomateiro Cereja Yubi de hábito determinado aconteceu separado temporalmente da parte generativa (frutos), isto é, a planta vegetou, floresceu e frutificou em períodos sequenciados, apresentando um número elevadíssimo 
Tabela 1. Produtividade de matéria fresca e seca da parte aérea total, das hastes, das folhas e dos frutos de sete genótipos de tomateiro avaliados em ambiente protegido no cultivo de outono/inverno em sistema hidropônico (shoots, stems, leaves and fruits fresh and dry matter production of seven tomato genotypes in greenhouse and hydroponic system in fall/winter crop-season). Pelotas, UFPel, 2010.

\begin{tabular}{|c|c|c|c|c|c|c|c|c|}
\hline \multirow{2}{*}{ Cultivares } & \multicolumn{4}{|c|}{ Matéria fresca $\left(\mathrm{kg} \mathrm{m}^{-2}\right)$} & \multicolumn{4}{|c|}{ Matéria seca $\left(\mathrm{g} \mathrm{m}^{-2}\right)$} \\
\hline & Parte aérea & Haste & Folhas & Frutos & Parte aérea & Haste & Folhas & Frutos \\
\hline Cereja Vermelho & $6,33 \mathrm{bc}$ & $1,92 \mathrm{ab}$ & $2,93 a b$ & $1,49 \mathrm{~cd}$ & $550,6 \mathrm{bc}$ & $153,4 \mathrm{ab}$ & $263,3 \mathrm{ab}$ & $134,0 \mathrm{~cd}$ \\
\hline Cereja Yubi det. & $7,98 \mathrm{ab}$ & $0,15 \mathrm{~d}$ & $4,78 \mathrm{a}$ & $3,05 \mathrm{bc}$ & $716,7 \mathrm{ab}$ & $11,7 d$ & $430,3 \mathrm{a}$ & $274,7 \mathrm{bc}$ \\
\hline Flavor Top & $4,09 \mathrm{c}$ & $1,20 \mathrm{bc}$ & $1,30 \mathrm{~b}$ & $1,59 \mathrm{~cd}$ & $356,0 \mathrm{c}$ & $95,7 \mathrm{bc}$ & $117,0 \mathrm{~b}$ & $143,3 \mathrm{~cd}$ \\
\hline Kada Gigante & $9,89 \mathrm{a}$ & $1,67 \mathrm{ab}$ & $2,78 \mathrm{ab}$ & $5,44 \mathrm{a}$ & $873,1 \mathrm{a}$ & $133,6 \mathrm{ab}$ & $249,8 \mathrm{ab}$ & $489,7 \mathrm{a}$ \\
\hline Gaúcho & $5,98 \mathrm{bc}$ & $0,80 \mathrm{~cd}$ & $1,37 \mathrm{~b}$ & $3,82 \mathrm{ab}$ & $530,4 \mathrm{bc}$ & $63,8 \mathrm{~cd}$ & $123,2 b$ & $343,4 a b$ \\
\hline Grape & $4,87 \mathrm{c}$ & $1,57 \mathrm{ab}$ & $2,63 \mathrm{ab}$ & $0,67 d$ & $422,3 \mathrm{c}$ & $125,6 \mathrm{ab}$ & $236,5 \mathrm{ab}$ & $60,3 d$ \\
\hline Pêra Amarelo & $5,82 \mathrm{c}$ & $1,96 \mathrm{a}$ & $2,86 a b$ & $1,00 \mathrm{~d}$ & $504,6 \mathrm{bc}$ & $156,8 \mathrm{a}$ & $258,0 \mathrm{ab}$ & $89,7 d$ \\
\hline
\end{tabular}

Médias seguidas de letras diferentes nas colunas indicam diferença significativa pelo teste de Tukey ( $<<0,05)$ (means followed by different letters in columns indicate significant difference by Tukey test $(\mathrm{P}<0.05)$.

Tabela 2. Altura da planta, área foliar e compacidade da planta (área foliar/altura) de sete genótipos de tomateiro avaliados em ambiente protegido no cultivo de outono/inverno em sistema hidropônico [plant height, leaf area and plant compactness (leaf area/plant height) of seven tomato genotypes hidroponically grown in fall/winter crop-season]. Pelotas, UFPel, 2010 .

\begin{tabular}{lccc}
\hline Cultivares & $\begin{array}{c}\text { Altura da planta } \\
(\mathbf{m})\end{array}$ & $\begin{array}{c}\text { Área foliar } \\
\left(\mathbf{m}^{\mathbf{2}} \mathbf{)}\right.\end{array}$ & $\begin{array}{c}\text { Compacidade da } \\
\text { planta }\left(\mathbf{m}^{\mathbf{2}} \mathbf{~ m}^{-\mathbf{}} \mathbf{)}\right.\end{array}$ \\
\hline Cereja Vermelho & $1,95 \mathrm{a}$ & $1,58 \mathrm{a}$ & $0,81 \mathrm{~b}$ \\
Cereja Yubi det. & $0,57 \mathrm{c}$ & $1,03 \mathrm{abc}$ & $1,81 \mathrm{a}$ \\
Flavor Top & $2,27 \mathrm{a}$ & $0,70 \mathrm{c}$ & $0,31 \mathrm{c}$ \\
Kada Gigante & $2,27 \mathrm{a}$ & $1,49 \mathrm{ab}$ & $0,66 \mathrm{bc}$ \\
Gaúcho & $1,73 \mathrm{~b}$ & $0,74 \mathrm{bc}$ & $0,43 \mathrm{bc}$ \\
Grape & $2,23 \mathrm{a}$ & $1,41 \mathrm{abc}$ & $0,63 \mathrm{bc}$ \\
Pêra Amarelo & $2,27 \mathrm{a}$ & $1,54 \mathrm{a}$ & $0,68 \mathrm{bc}$ \\
\hline
\end{tabular}

Médias seguidas de letras diferentes nas colunas indicam diferença significativa pelo teste deTukey $(p<0,05)$ (means followed by different letters in columns indicate significant difference by Tukey test $(\mathrm{P}<0.05)$.

de brotações laterais, as quais foram mantidas. Desta forma, este genótipo apresentou grande quantidade de folhas, igualando-se à maioria dos demais e, inclusive, superando alguns em relação à produção de MF e MS destes órgãos.

Em relação à produtividade de frutos (MF e MS), foram superiores os genótipos Kada Gigante e Gaúcho, como era esperado e, entre os minitomates, salientou-se o Cereja Yubi de hábito determinado, que, inclusive, apresentou MF e MS de frutos estatisticamente semelhantes ao Gaúcho. Os tomates Cereja Vermelho e Flavor Top apresentaram produtividade de frutos estatisticamente semelhante a do tomate Cereja Yubi. Os tomates Grape e Pêra Amarelo apresentaram os valores mais baixos com o tomateiro Monte Carlo $(5,22 \mathrm{~kg}$ $\mathrm{m}^{-2}$ ) estabelecido na densidade de 3,3 plantas $\mathrm{m}^{-2}$ em cultivo de outono no Rio Grande do Sul.

Rocha (2009), estudando a dinâmica de crescimento da cultura do tomateiro Cereja Vermelho de crescimento indeterminado, cultivado em sistema hidropônico na densidade de 3,4 plantas $\mathrm{m}^{-2}$, durante o ciclo de verão/outono no Rio Grande do Sul, obteve produção média final de matéria seca acumulada nos frutos, nas folhas e na haste de 216,0; 312,14 e $295,0 \mathrm{~g} \mathrm{~m}^{-2}$, respectivamente. Neste trabalho, como esperado, devido às condições de baixa luminosidade e temperatura do ciclo de outono/inverno, os valores médios obtidos para este mesmo genótipo foram inferiores (respectivamente, 134,0;263,3 e 153,4 g $\mathrm{m}^{-2}$ ). Entretanto, o genótipo Cereja Yubi determinado apresentou produção de MS dos frutos de 274,7 $\mathrm{g} \mathrm{m}^{-2}$, indicando uma maior adequação deste genótipo às condições de outono/inverno.

Partição de fotoassimilados - Em relação à partição de matéria seca, pode-se observar na Figura 1, que os genótipos apresentam distribuição de fotoassimilados bem diferenciada. Os genótipos Grape e Pêra Amarelo apresentaram maiores acúmulos de matéria seca na parte vegetativa ( 86 e $83 \%$, respectivamente) em detrimento da parte generativa, sendo que os frutos representaram, respectivamente, somente 14 e $17 \%$ da matéria seca aérea das plantas nestes genótipos. Os genótipos Cereja Yubi e Flavor Top apresenta- 


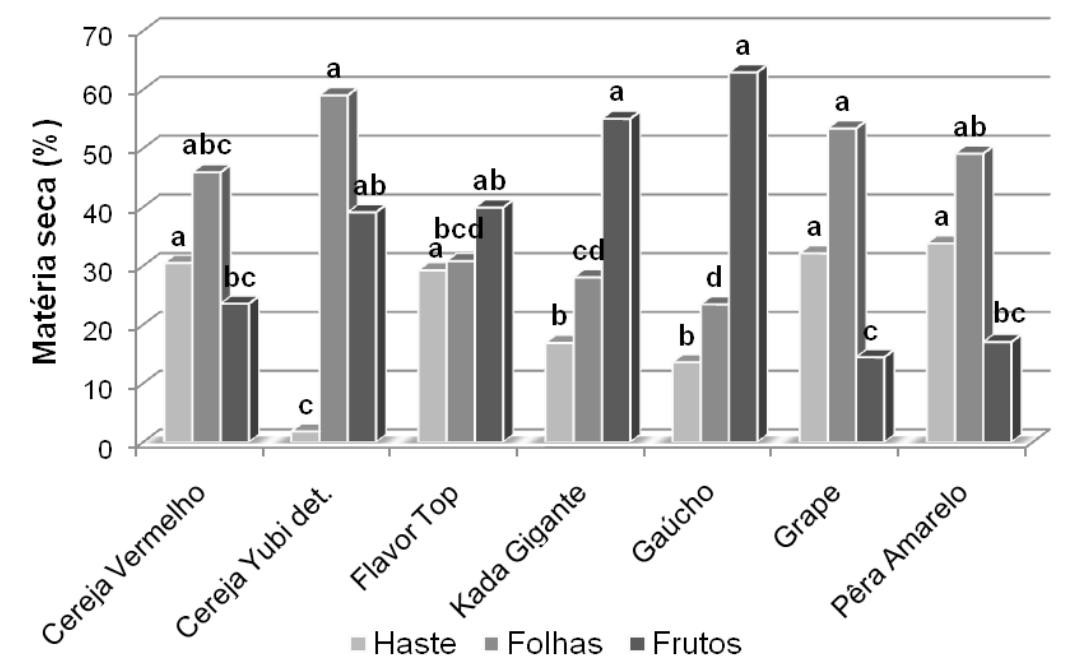

Figura 1. Partição da matéria seca entre hastes, folhas e frutos de genótipos de tomateiro cultivados em sistema hidropônico em outono/inverno (dry matter partitioning among stems, fruits and leaves of tomato genotypes grown in hydroponic system during fall-winter crop-season); médias representadas por barras com diferentes letras apresentam diferença significativa pelo teste de Tukey $(\mathrm{p}<0,05)$ (means represented by different letters present siginificant difference by Tukey test $(\mathrm{p}<0.05))$. Pelotas, UFPel, 2010.

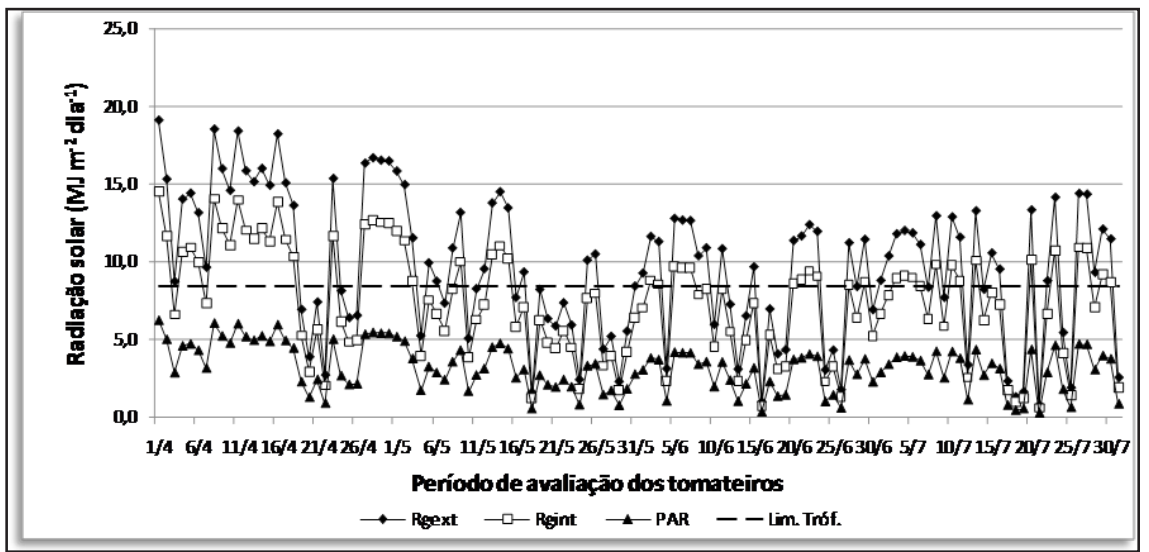

Figura 2. Radiação solar global externa $\left(\operatorname{Rg}_{\text {ext }}\right)$ medida na Estação Agroclimática da UFPel $\left(32^{\circ} 42^{\prime} \mathrm{S}, 52^{\circ} 24^{\prime} \mathrm{O}\right)$, radiação solar global interna $\left(\mathrm{Rg}_{\text {int }}\right)$ e radiação fotossinteticamente ativa (PAR) calculadas para o interior da casa de vegetação e limite trófico (Lim. Tróf.) para tomateiro [solar global radiation $\left(\mathrm{Rg}_{\text {ext }}\right)$ measured in "Estação Agroclimática da UFPel $\left(32^{\circ} 42^{\prime} \mathrm{S}\right.$, $52^{\circ} 24^{\prime} \mathrm{O}$ ), solar global radiation $\left(\mathrm{Rg}_{\text {int }}\right)$ and photosynthetic active radiation (PAR) calculated inside the greenhouse and trofic limit for tomato crop]. Pelotas, UFPel, 2010.

ram uma partição de fotoassimilados mais equilibrada, com 61 e $60 \%$ na parte vegetativa e 39 e $40 \%$ nos frutos, respectivamente. A análise também demonstra que no genótipo Cereja Yubi determinado, a produção de hastes em relação aos outros órgãos é pequena, visto o pequeno comprimento dos entrenós. Os tomateiros Kada Gigante e Gaúcho, pela característica de produzirem frutos grandes, alocaram maior proporção de fotoassimilados para o desenvolvimento da parte generativa, 55 e $63 \%$, respectivamente.

Andriolo et al. (2000), estudando a posição dos frutos e seu efeito na repartição da matéria seca da planta do tomateiro híbrido longavida "Diva" em ciclos de primavera e de outono, constatou que, na média, as plantas acumularam mais matéria seca e mobilizaram cerca de $38 \%$ dos fotoassimilados para os frutos, quando cultivadas na primavera, época de radiação solar crescente, enquanto no outono a média do acúmulo de matéria seca foi menor, mobilizando $29 \%$ para a formação e crescimento de frutos.

Altura, área foliar e compacidade Os genótipos de crescimento indeterminado apresentaram alturas semelhantes, em torno de 2,0 m, excluindo o Gaúcho que alcançou 1,72 m (Tabela 2). E, como esperado, o genótipo Cereja Yubi de crescimento determinado diferiu dos demais, atingindo apenas $0,57 \mathrm{~m}$ de altura, inferindo-se que a produção de frutos independe da altura das plantas, estando relacionada ao potencial generativo e produtivo do genótipo.

A área foliar (Tabela 2) dos genótipos Pêra Amarelo e Grape, embora estatisticamente semelhante à dos genótipos Cereja Vermelho, Cereja Yubi e Kada Gigante, não correspondeu a uma resposta fotossintética que se refletisse na produção de frutos. Os valores de área foliar apresentados pelos genótipos foram semelhamentes aos alcançados pelo genótipo Cereja Vermelho de 0,75 a 1,40 m², em estudo de Rocha (2009).

Verificou-se, também que o genótipo Cereja Yubi de crescimento determinado apresentou o maior índice de compacidade (Tabela 2), caracterizando plantas rasteiras, que resultaram em cobertura mais densa e rápida da área de cultivo.

Radiação solar - A radiação solar global externa acumulada durante o período experimental foi de 1180,36 $\mathrm{MJ} \mathrm{m}^{-2}$, sendo a radiação global e a PAR incidentes no interior da casa de vegetação estimadas em 897,07 e 358,85 $\mathrm{MJ} \mathrm{m}^{-2} \mathrm{dia}^{-1}$.

A média da radiação solar interna diária estimada, segundo índice de correção para radiação global interna obtido por Beckmann et al. (2006), foi de 7,35 $\mathrm{MJ} \mathrm{m}{ }^{-2} \mathrm{dia}^{-1}$ (Figura 2), valor inferior ao limite trófico para o tomateiro que é de 8,4 $\mathrm{MJ} \mathrm{m}^{-2}$ dia $^{-1}$ (FAO, 1990; Andriolo, 1999). Com base nestes valores, poder-se-ia inferir que as plantas não apresentariam crescimento adequado e desenvolvimento satisfatório, visto que de maneira geral, o desenvolvimento normal das culturas ocorre quando a quantidade de radiação recebida é superior ao nível trófico. No entanto, em 53 dias do total de 121 dias de cultivo, o que corresponde a $43,8 \%$ do ciclo, a radiação solar manteve-se acima do limite trófico 


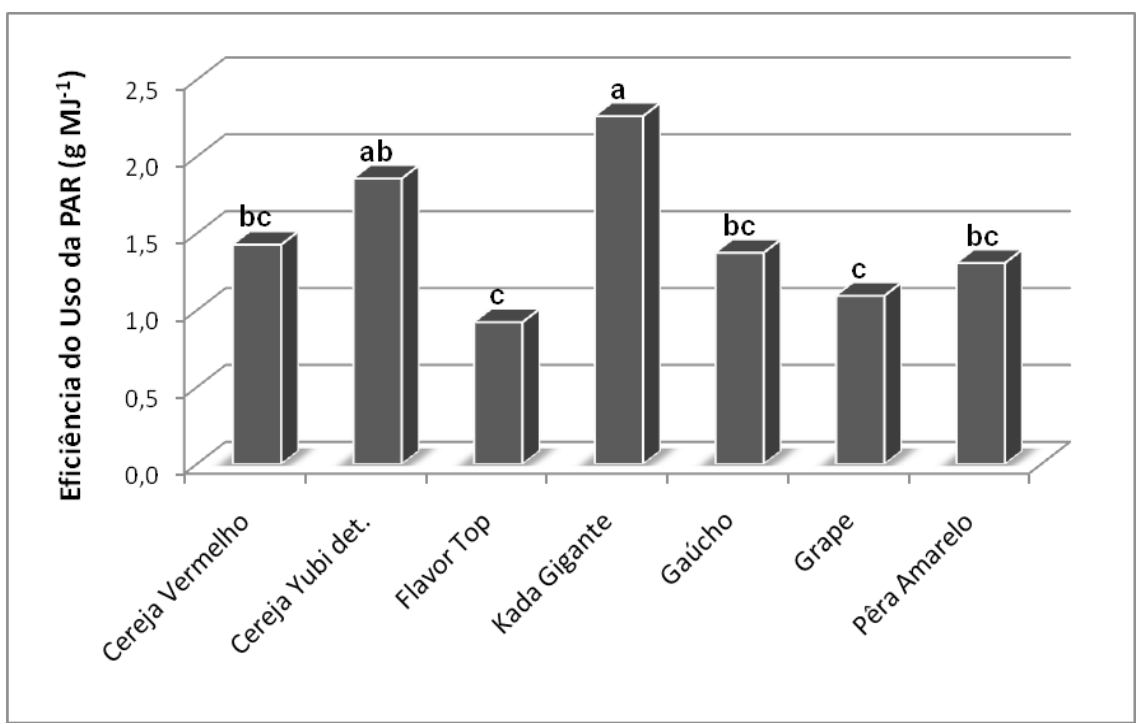

Figura 3. Eficiência no uso da PAR incidente no interior da casa de vegetação de genótipos de tomateiro cultivados em sistema hidropônico em outono/inverno (PAR use efficiency of tomato genotypes grown in hydroponic system during fall-winter crop-season). Pelotas, UFPel, 2010.

(Figura 2), sendo suficiente para que os tomateiros crescessem, emitissem flores e produzissem frutos que atingiram o amadurecimento completo.

Eficiência no uso da radiação solar fotossinteticamente ativa (PAR) incidente - A análise de variância dos dados de eficiência no uso da PAR incidente no interior da casa de vegetação demonstrou que houve diferenças significativas pelo teste $F(p<0,05)$ entre os genótipos de tomateiro. Os genótipos Kada Gigante e Cereja Yubi de crescimento determinado apresentaram maior eficiência, com valores de 2,26 e 1,86 g MS $\mathrm{MJ}^{-1}$, respectivamente (Figura 3). Estes resultados são próximos aos obtidos por Radin et al. (2003) para a cultura em casa de vegetação, os quais foram, em média, de 2,43 $\mathrm{g} \mathrm{MJ}^{-1}$ no ciclo de verão/outono. Andriolo \& Falcão (2000), verificando o efeito da poda de tomateiros cultivados na densidade de 6,7 plantas $\mathrm{m}^{-2}$, obtiveram uma eficiência no uso da PAR de 1,6 g MS MJ ${ }^{-1}$ em cultivo de verão/outono no Rio Grande do Sul. Estes dados demonstram claramente que a eficiência no uso da radiação está relacionada com o genótipo do tomateiro. Pode-se dizer que os valores de eficiência no uso da PAR incidente obtidos neste trabalho foram bastantes elevados, considerando as condições de cultivo em casa de vegetação não climatizada. Isso pode creditar-se aos baixos valores de radiação solar no período, uma vez que a eficiência no uso da PAR, segue a lei dos acréscimos decrescentes em que, quanto mais próximo do limite trófico, mais eficiente o uso da radiação solar (Aikman, 1989).

Através das respostas obtidas para os sete genótipos de tomateiros no ciclo de outono/inverno no sul do Brasil, em hidroponia, pode-se concluir que a eficiência no uso da radiação PAR incidente e a produtividade biológica estão diretamente relacionadas com o genótipo. Os genótipos mais promissores para o cultivo em épocas de baixa disponibilidade de radiação solar são o Kada Gigante, do tipo Santa Cruz, e o Cereja Yubi de crescimento determinado, do grupo dos minitomates, por apresentarem produtividade de materia fresca e seca do total da parte aérea e dos frutos superiores, demonstrando uma alta eficiência no uso da PAR. Sob as condições da pesquisa, os genótipos pertencentes ao grupo dos minitomates apresentam maior partição proporcional de materia seca para a formação de folhas, em prejuizo da formação dos frutos, quando comparados com os genótipos de frutos maiores.

\section{REFERÊNCIAS}

AGRIANUAL. Tomate. São Paulo: FNP, p. 493504, 2010.
AIKMAN DP. 1989. Potential increase in photosynthetic efficiency from the redistribution of solar radiation in a crop. Journal of Experimental Botany 29: 815-827.

ANDRIOLO JL. 1999. Fisiologia das culturas protegidas. Santa Maria: Ed. UFSM. 142p., il.

ANDRIOLO JL; FALCÃO LL. 2000. Efeito da poda de folhas sobre a acumulação de matéria seca e sua repartição para os frutos do tomateiro cultivado em ambiente protegido. Revista Brasileira de Agrometeorologia 8: 75-83.

ANDRIOLO JL; DUARTE TS; LUDKE, L; SKREBSKY EC. 1997. Crescimento e desenvolvimento do tomateiro cultivado em substrato com fertirrigação. Horticultura Brasileira 15: 28-32.

ANDRIOLO JL; LUDKE L; DUARTE TS; SKREBSKY EC. 2000. Posição dos frutos e seu efeito na repartição da matéria seca da planta do tomateiro. Ciência Rural 30: 235-240.

ANDRIOLO JL; ESPÍNOLA MCG; GODÓI R; BORTOLOTTO OC; LUZ GL. 2004a. Crescimento e produtividade de plantas de tomateiro em cultivo protegido sob alta densidade e desfolhamento. Ciência Rural 34: 1251-1253.

ANDRIOLO JL; WITTER M; ROSS T; GODOI RS. 2004b. Crescimento, desenvolvimento e produtividade do tomateiro cultivado em substrato com três concentrações de nitrogênio na solução nutritiva. Ciência Rural 34: 14511457.

BECKMANN MZ; DUARTE GRB; PAULA VA; MENDEZ MEG; PEIL RMN. 2006. Radiação solar em ambiente protegido cultivado com tomateiro nas estações verão-outono do Rio Grande do Sul. Ciência Rural 36: 86-92.

CEASA-RS. Centrais de Abastecimento do Rio Grande do Sul SA. 2011, 6 de janeiro. Cotações. Disponível em http://www.ceasa. rs.gov.br/

DUARTE LA; SCHÖFFEL ER; MENDEZ MEG; SCHALLENBERGER E. 2011. Alterações na temperatura do ar mediante telas nas laterias de ambiente protegido cultivado com tomateiro. Revista Brasileira de Engenharia Agrícola Ambiental 15: 148-153.

FAO. 1990. Protected cultivation in the Mediterranean climate. Roma: FAO, 313p. (Plant Production and Protection Paper, 90)

GUSMÃO SAL; PÁDUA JG; GUSMÃO MA; BRAZ LT. 2000. Efeito da densidade de plantio e forma de tutoramento na produção de tomateiro tipo "cereja". Horticultura Brasileira, v.18, Suplemento.

NUEZ F. 2001. El cultivo del tomate. Madrid: ed. Mundi-prensa, $793 \mathrm{p}$.

PAPADOPOULOS AP; PARARAJASINGHAM S; SHIPP JL; JARVIS WR; JEWETT TJ; CLARKE ND. 1997. Integrated management of greenhouse vegetable crops. Horticultural Reviews 21: 1-39.

PEREIRA AR; ANGELOCCI LR; SENTELHASPC. 2002. Agrometerologia: fundamentos e aplicações práticas. Guaíba: Agropecuaria, 478p.

RADIN B; BERGAMASCHI H; REISSER 
JÚNIOR C; BARNI NA; MATZENAUER R; DIDONÉ IA. 2003. Eficiência de uso da radiação fotossinteticamente ativa pela cultura do tomateiro em diferentes ambientes. Pesquisa Agropecuária Brasileira 38: 10171023.

RATTIN JE; ANDRIOLO JL; WITTER M. 2003. Acumulação de massa seca e rendimento de frutos de tomateiro cultivado em substrato com cinco doses de solução nutritiva. Horticultura Brasileira 21: 26-30.

ROCHA MQ. 2009. Crescimento, Fenologia e
Rendimento do tomateiro cereja em cultivo hidropônico. Pelotas: UFPEL-FAEM. 129p. (Tese mestrado).

SANTOS MR; SEDIYAMA MAN; PEDROSA MW; VIDIGAL SM; NOBRE MCR. 2006. Desempenho de cultivares de tomate tipo cereja em cultivo orgânico. In: CONGRESSO BRASILEIRO DE OLERICULTURA, 46. Anais... Goiana: SOB (CD-ROM)

TANAKA A; FUJITA K; KIKUCHI K. 1974. Nutri-Physiological studies on the tomato plant: I Outline of growth and nutrient absorption. Soil Science Plant Nutrition 20: 57-68.

TAIZ L; ZEIGER E. 2009. Fisiologia vegetal. Porto Alegre: Artmed. 819p.

VALANDRO J; BURIOL G; ANDRIOLO JL; HELDWEIN AB. 2007. Transpiração do tomateiro cultivado fora do solo em estufa plástica e sua relação com os elementos meteorológicos. Ciência Rural 37: 1593-1600. 